\title{
An early grade science, technology, engineering and mathematics dialogue reading programme: The development of a conceptual framework
}

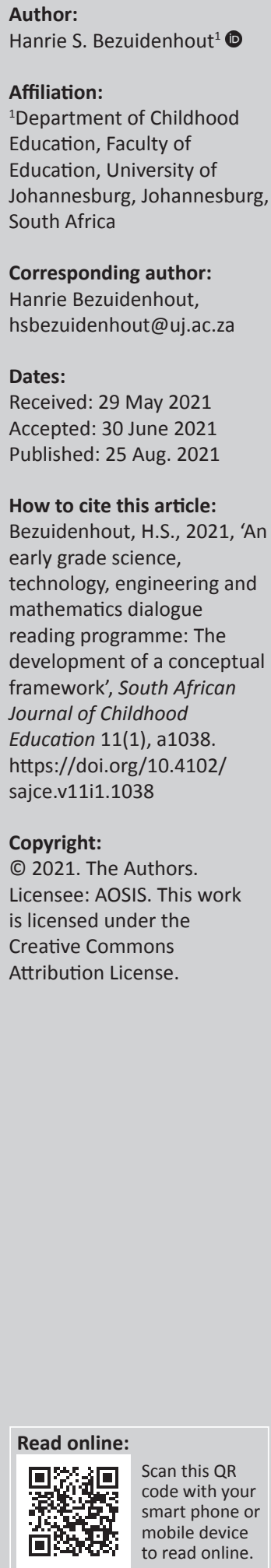

Background: The South African Department of Basic Education (DBE) aims to expand science, technology, engineering and mathematics (STEM) learning in the national curriculum through a Digital Skills for All Curriculum (DSfAC) for Grade R - 9. The DSfAC intends to educate a STEM-literate future citizenry with refined computational thinking $(\mathrm{CT})$, and coding and robotics skills. As with all learning, foundations are ideally laid when children are young and when they form habits of thinking that can ultimately serve as their first building blocks for successful learning. Current theoretical frameworks describe how teachers can include CT, coding and other STEM related constructs in their teaching. In the curriculum plan, a conceptual framework that underpins the design of teaching materials to support STEM literacy teaching, has, however, not yet been forwarded.

Aim: Presenting a conceptual framework that has served as the design heuristic for a dialogue reading programme (DRP) for young children. The programme consists of three picture books, created to develop young children's digital skills and related vocabulary as outlined in the DSfAC through story texts and pictures.

Method: I implemented an iterative participatory approach to develop the conceptual framework.

Conclusion: The development of teaching materials, like a DRP, should have its genesis in a confluence of three interdisciplinary components to develop a conceptual framework: (1) scientific research and theories; (2) an iterative participatory approach which involves teachers, parents, children, and other role players in the development process; and (3) systematic utilisation of existing examples of relevant teaching materials.

Keywords: STEM education; dialogue reading; artificial intelligence; conceptual framework; early grades; computational thinking; coding; digital skills.

\section{Introduction}

Purpura et al. (2017), proponents of dialogue reading as a pedagogical tool for early grade teachers and parents, argue for its broader use. The authors note that it is underused and could serve as a vehicle to expand vocabulary and, with that concept development in an intersect of the disciplines of science, technology, engineering and mathematics (STEM). To develop a dialogue reading programme (DRP), which aims to advance STEM literacy in the early grades, requires an assemblage of: (1) theoretical and scientific knowledge of how young children learn (e.g. Clements \& Sarama 2016; Dehaene 2020); (2) repetitive input from experts in the applied fields of STEM and education, as well as parents and children (e.g. John et al. 2018); and (3) careful investigation of existing examples of teaching material (particularly stories) in the STEM disciplines (Clements \& Sarama 2016). Although a few theoretical frameworks for teaching STEM literacy exist (Chu, Martin \& Park 2019; Greca Dufranc et al. 2020; Kelley \& Knowles 2016), the resources with specific instructional guidelines for early grade teachers and parents are limited (Chu et al. 2019). Also, these existing frameworks mostly focus on elementary grade STEM education and explain how teachers can plan to integrate the disciplines of STEM in lessons and not specifically on a framework to ground the development of teaching material that can support teachers in doing so. There is, furthermore, no existing conceptual framework that grounds the development of a DRP to support STEM literacy education in the early grades. This is why Clements and Sarama (2015) highlights the idea that research informed programmes that can scaffold young children's learning, should take precedence in early STEM literacy education. 

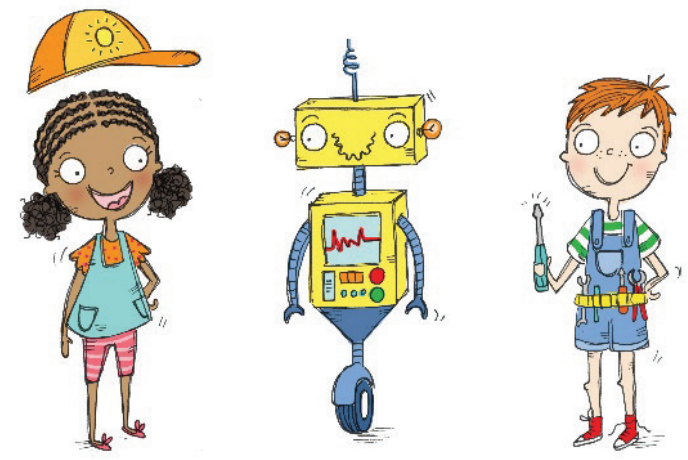

FIGURE 1: Kate, Alex and Ben: Characters for science, technology, engineering and mathematics dialogue reading programme reading books.

The purpose of this article is to describe the conceptual framework that was used to develop a DRP for early STEM literacy. I set out to respond to the question: How can the design of a conceptual framework serve as theoretical groundwork for the development of a DRP for early grade STEM literacy education? I propose that an interdisciplinary conceptual framework can serve as the bedrock from which how early grade South African children can attain the STEM skills included in the new Digital Skills for All Curriculum (DSfAC) through 'dialogue reading' can be explored. Purpura et al. (2017) propose that:

$[D]$ ialogue reading involves a role shift ... [where] the child becomes the storyteller while the adult uses questions and prompts and adds information in order to scaffold the child's language development. (p. 119)

The reading activity becomes a dialogue, rather than a listening activity. In a developmentally appropriate DRP, children can 'participate' in an interactive fashion and take part in the discussions between the characters in the books. Figure 1 shows the characters that feature in the three picture books.

\section{Emergent science, technology, engineering and mathematics skills in the South African early grade curriculum}

The South African Department of Basic Education (DBE) aims to strengthen STEM literacy in the national curriculum through a DSfAC for Grade R - 9 (DBE, in press). The DSfAC includes computational thinking (CT), coding and robotics in the term 'digital skills'. Bybee (2010:996) proposes that the purpose of STEM education is to equip children with the necessary skills to ultimately establish 'a STEM-literate citizenry prepared to address the grand challenges of the 21st century'. Unfortunately, 'studies show that the country lags behind in the information technology skills needed for the digital revolution' (https://www.gov. $\mathrm{za} / \mathrm{ss}$ / speeches / president-cyril-ramaphosa-2021-basiceducation-sector-lekgotla-25-feb-2021).
The purpose of the DSfAC (DBE, in press) is to respond to a proposition, such as Bybee's (2010), equipping children with skills required in a 21st century society and to build economic communities that can flourish in a fourth industrial revolution (4IR) world. Increasingly, STEM skills, including 'digital skills', are foundational in a technology-saturated society. Yet, less than $9 \%$ of South African learners are currently enrolled for school subjects that develop their 'digital skills' at Further Education Training (FET)-level and no digital skills are currently included in the early grades curriculum (DBE, in press).

The DSfAC consists of four pillars: (1) CT skills and coding; (2) data and information management skills; (3) internet and e-communication skills; and (4) application skills, with CT as the basis from which the programme will be approached (DoE, in press:8). In the foundation phase (Grade $R-3$ ), the four pillars will be integrated into the existing subjects of literacy, numeracy and life skills.

The first pillar, which focuses on CT and which also forms the foundation of the curriculum, is situated within the STEM disciplines because CT can be readily applied in problem solving in STEM. Lu and Fletcher (2009) suggests that CT should be used to prepare young children for coding and other digital technology applications such as robotics. I would add that there should be coherence within the STEM learning areas and that an organising pedagogical mechanism could, for example, be CT. Wing (2008) also suggests introducing CT as a formative skill together with literacy and numeracy which is what I aim for with the DRP for early grade STEM literacy.

The DSfAC defines CT as a problem-solving process that includes a number of characteristics, such as logically ordering and analysing data and creating solutions using a series of ordered steps (or algorithms), and dispositions, such as the ability to confidently deal with complexity and openended problems. CT requires the use of abstraction, decomposition, pattern recognition, data representation, generalisation and modelling (DBE, in press:6).

The envisaged curriculum concentrates on teaching children how to solve real world problems and to develop children's vocabulary, allowing them to describe possible solutions to problems and to reflect on their own solutions as well as those of others. That is why storytelling and interactive discussions about relevant STEM concepts are vital. In the foundation phase, children will also be taught to follow the scientific/ engineering design process to help them plan and build simple robots, associated with movement, by following a verbal (natural language) or pictorial algorithm/plan such as the programming language tool, ScratchJr (Bers 2018; https:/ / www.scratchjr.org/; https://scratch.mit/edu/boost).

Yet, apart from this, no teaching materials are recommended in the curriculum with which to apply the theoretical ideas 
described in the curriculum. The purpose of developing a DRP for early STEM literacy is to address this void by providing early grade teachers and parents with a practical tool to scaffold CT, vocabulary development and concept learning before they are exposed to the robotics curriculum at school. I argue that a practical teaching tool like the DRP can be utilised to initiate young children into the world of CT and specifically to achieve the foundational goals of the DSfAC. The DRP is designed to serve as examples of how children can create, invent, experiment, reflect and discuss solutions to real life problems and to develop their creativity and their critical thinking that the DSfAC requires.

\section{Conceptual framework: The design of an early grades science, technology, engineering and mathematics literacy dialogue reading program}

Dufranc et al. (2020:5) propose that a framework that underpins didactical/instructional material should 'address pedagogy and content within an integrated STEM education'. To develop a conceptual framework that could form the bedrock for a DRP for STEM literacy in the early grades, I focused on integrating (1) theories about how learning through language, and theories about CT, coding and other digital skills; (2) the advice of practicing experts in both education and the applied fields of engineering, coding and programming; and (3) examples of existing teaching materials.

I implemented an iterative participatory approach to the research plan for this article (Holt \& Asagbra 2021; John et al. 2018). At the outset of the ongoing research project that was started in 2020 and in which I aim to write a series of three children's books that can be utilised in the early grades to teach STEM concepts, I discussed many ideas with parents of young children and early grades teachers. During these conversations, most of the discussants referred to the components of digital skills which are modelled in existing stories on television. An existing DRP for early grade numeracy (Purpura et al. 2017, in press) also came up in the discussions regarding the layout and style of the books. I aimed to integrate the components of these discussions with existing theory about how children learn. I am familiar with such theories in the fields of developmental cognitive psychology (e.g. Carey 2009; Carey, Zaitchik \& Bascandziev 2015; Clements \& Sarama 2016) and developmental cognitive neuroscience (e.g. Ansari 2017; Dehaene 2011, 2020), specifically theories that describe the role of language in learning (e.g. Chomsky 2014; Dehaene 2009, 2013; Gallistel \& King 2011; Gopnik \& Meltzoff 1997; Levine \& Baillargeon 2016; Vygotsky 1978, 1986) and with the idea that a theoretical/conceptual model should form the bedrock of design for educational material (Bezuidenhout 2018; De Villiers 2015). Yet, I did not previously consider the importance of existing story examples, or the value of an iterative participatory approach (Holt \& Asagbra 2021; John et al. 2018) that incorporates the knowledge of many role players such as parents, teachers and children. The initial discussions with parents and teachers led to the composition of a conceptual model to ground the project by amalgamating theoretical knowledge of how children learn with the ideas of parents, teachers, children and other community members - which included references to for example, artificial intelligent robots and their application of digital skills and other STEM components in existing stories.

Figure 2 shows how the intersect of the three core componentstheory, participation of various role players and existing stories as examples - collectively outlined the process of designing five aspects that constitute the DRP. Each aspect is discussed in the next section:

1. story topics that provide ample opportunities to discuss the identified digital skills of STEM literacy;

2. characters that elicit curiosity;

3. digital skills vocabulary as outlined in the DSfAC, and which the books intend to 'teach';

4. constructs of design and STEM thinking must be portrayed in the story lines; and

5. illustrations that support the text.

The series was named Robot Dilemmas and consists of a collection of three dialogic reading picture books. It was designed to scaffold children's CT, and their coding and programming vocabulary while they identify with story characters; the characters solve problems, create new things in an experimental fashion and think logically. Figure 3 shows an example scenario in which learners can identify with the characters who must solve a problem. In this picture, Alex is moving too fast on a hiking trip with his two friends. As a result of the way in which Ben programmed the little robot, Alex keeps tripping over rocks and tree roots.

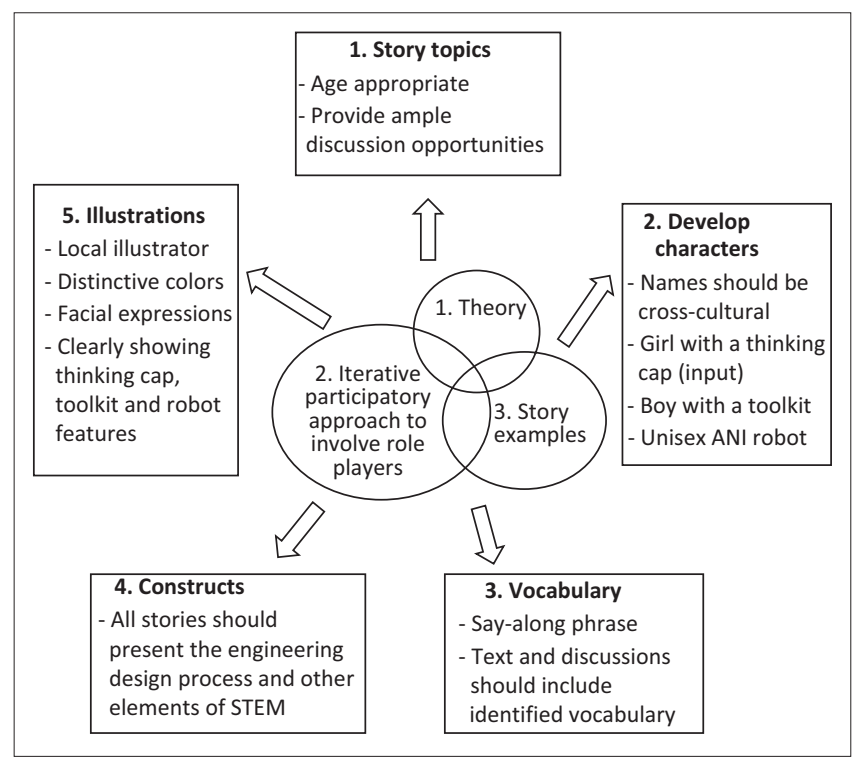

STEM, science, technology, engineering and mathematics; ANI, artificial narrow intelligent. FIGURE 2: Conceptual framework as bedrock for a dialogic reading programme design. 


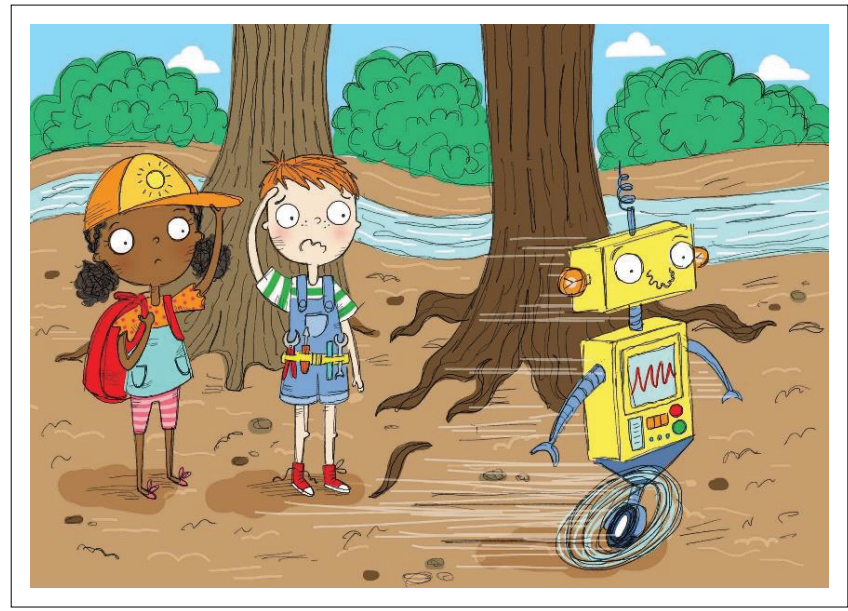

FIGURE 3: An example of a scene in Alex gets stuck where the robot's code must be modified.

Subsequently, Kate explains to Ben how the code should be adjusted so that the problem can be solved.

The books can serve as pathways to get acquainted with new words and their meaning, with which to build concepts and develop an intuition for coding language. Through repeated dialogic readings and discussions, children can internalise new vocabulary, preparing them for the digital (coding and robotics) curriculum which will soon be introduced into foundation phase classrooms. In the following section of this article, I describe the three central components of the conceptual framework and I report on how each component of the conceptual framework featured in the development of the Robot Dilemmas book series.

\section{Core component 1: Theoretical domains}

The theories included in the conceptual framework are an amalgam of various perspectives on (1) how children learn through language (including the use of dialogue reading); (2) the principles of CT, coding and other digital skills; and (3) how the language skills and STEM literacy were integrated in the stories.

\section{Learning through language}

\section{Dialogic reading}

In 1988, Whitehurst and his colleagues (Whitehurst et al. 1988) found that reading with young children through what they termed 'dialogic reading' contributes to vocabulary development. Based on this view, the purpose of dialogic reading is to 'teach' language by eliciting oral responses from children, using evocative techniques such as prompts and questions and giving informative feedback. Adult readers are encouraged to use the prompt, evaluate, expand and repeat (PEER) and completion, recall, open-ended, whquestions, distancing (CROWD) interaction techniques to scaffold language interactions between themselves and the children (Holt \& Asagbra 2021). These strategies encourage the child to become a co-storyteller, to repeat and expand the child's speech, and to provide corrective feedback on the child's use of language.

Each page of the book includes the text of the story and example questions that the reader can ask about the narrative. The adult reader is encouraged to adjust questions according to the child's responses, constantly engaging children in the storytelling process (Mol et al. 2008; Purpura et al. 2017, in press). Oral interaction between the reader and the children invites them to become the storytellers just as much as the reader (Mol et al. 2008). Table 1 provides examples of the text, questions and suggestions for the reader.

When hearing language in direct conversation, children respond spontaneously and often try to use the new words that they have heard. In the stories, new words are introduced systematically, giving them the opportunity to engage in a scaffolding process of language development, and with that, there is the possibility of conceptual development. Sulzby (1985) argues that shared reading provides the experiences to utilise everyday talk, while also introducing new vocabulary. Tunmer and Hoover (2019) explain that words on their own have less significance than words in a sentence, such as the informal talk that happens when the book content is discussed with a child. They advise that language form/ structure should feature in learning to understand written (and spoken) language. Various linguistic aspects should be considered when new vocabulary is introduced to young children.

\section{Linguistic aspects of conceptual development}

Conceptual development is not independent from linguistic development (Dowker \& Nuerk 2016; Kozulin 1990; Purpura et al. 2019; Spelke 2017; Tunmer \& Hoover 2019). One cannot introduce STEM concepts through a reading programme without considering various levels of linguistic aspects of learning. Vygotsky (Kozulin 1990; Vygotsky 1986) proposed that language and ideas intersect when language becomes a medium of thought and thought becomes verbal. ${ }^{1}$ There is thus a constant interaction between conceptual development and linguistic development. A DRP capitalises on this type of interaction.

Dowker and Nuerk (2016) distinguishes between different levels of linguistic influences. On a phonological level, children learn the sound structures of a language and often the meaning of the words also. Lexical [vocabulary] development depends on word occurrence frequency, phonological familiarity with the sounds and sound structures of a language and of new words, as well as a child's developmental stage. Syntax also plays a role in learning new words (Tunmer \& Hoover 2019). The word order and the grammar conventions add much to the process of meaning and making of new words; for example, singular and plural nouns and their concord with verbs as well as the tense structures of 1.The term "verbal' refers to language per se, whether spoken or written. 
TABLE 1: Extracts from the dialogue reading programme.

\begin{tabular}{|c|c|}
\hline Book & Extract \\
\hline Alex Gets Stuck & $\begin{array}{l}\text { 'If Alex comes along, we definitely need to plan our trip carefully!' suggested Ben. } \\
\text { 'No problem!' said Kate while putting on her thinking cap and activating her thinking screen. } \\
\text { 'All right Alex,' said Ben. 'I've got the tools, Kate's got her thinking cap. We are ready to Alexify! We are ready to customise, modify and deploy!' } \\
\text { Ben took out his toolkit and opened up the input screen on Alex's tummy. } \\
\text { 'Ben, you definitely need to make sure that the programming script is the same as the map of the hiking trail. Then Alex will also know where to go. } \\
\text { Make sure to include every single thing on that map in the code!' } \\
\text { 'Yes ma'am', joked Ben while inputting the codes of every corner and turn on the map. He didn't want Alex to get lost during the hike! } \\
\text { - Can Alex think for itself? Why not/why? } \\
\text { - Why does Ben need to programme Alex? } \\
\text { - What input does Ben give Alex? } \\
\text { These questions address the idea that robots need inputs/instructions; they cannot think for themselves but can learn through repetitions and } \\
\text { adjustments. }\end{array}$ \\
\hline Road Trip with Alex & $\begin{array}{l}\text { 'I wonder how we could travel to the mountains...' said Kate. 'We are too young to drive ourselves!' She reached for her thinking cap and put it on. } \\
\text { After thinking for a while she said, 'I have a brilliant idea! We can programme Alex to become a self-driving car and then our robot friend can take us to } \\
\text { the mountains!' 'Great idea,' said Ben. 'We should plan carefully. I am ready to Alexify! Customise, modify and deploy!' he shouted excitedly. Ben } \\
\text { grabbed his toolkit. } \\
\text { - What is a self-driving car? (Cars that can drive without human drivers) } \\
\text { - Are there any self-driving cars in your country? (Although some cars can park, adjust speed, have GPS, there aren't yet any self-driving cars) } \\
\text { - What do you think are the important things that a self-driving car should have? (GPS, sensors to monitor things around the car like trees, cars and } \\
\text { people, the ability to adjust speed, be able to park itself) } \\
\text { Focus on the principles of self-driving cars: there are a few cars that can park on its own and there are things like speed control. There are no } \\
\text { self-driving cars on South Africa's roads, yet. }\end{array}$ \\
\hline Alex's recycling challenge & $\begin{array}{l}\text { 'All right Ben,' said Kate. } \\
\text { 'First, you will have to write a code that tells Alex which items can be recycled and which ones not. Alex will have to separate food from recyclable } \\
\text { waste like tins, paper, cardboard, plastic and glass,' explained Kate. } \\
\text { 'How will Alex know how to do that?,' asked Ben. } \\
\text { 'Most of the plastic bottles, glass bottles, cardboard and tins have the recycle sign,' said Kate. 'Alex can look out for this sign.' } \\
\text { 'Done,' said Ben after programming Alex to look out for the recycling sign. 'Alex will put all the items with the recycling sign on one pile and put all the } \\
\text { food items in the black dustbin,' said Ben. } \\
\text { - Why won't Alex know by itself which items are recyclable and which are not? } \\
\text { - Who can tell Alex which items are recyclable and which are not? Do you think you will be able to tell a robot what to do? } \\
\text { - How can Ben and Kate tell Alex which items are recyclable and which ones are not? (Through coding and not spoken language). } \\
\text { Alex is a robot and a robot doesn't have a brain like a human. Humans can tell robots what to do by programming the robot through coding. We can } \\
\text { train a robot to make decisions, but a robot cannot think for itself without human input. }\end{array}$ \\
\hline
\end{tabular}

the verbs of a language together lead to understanding and, thus, semantic effects (Sarnecka 2014).

Particularly relevant to the development of a DRP, is the proposition that vocabulary knowledge influences conceptual development: unfamiliar words can obstruct children's understanding and it also makes it difficult for them to follow instructions arising from the text; familiar words, in contrast, scaffold understanding. The purpose of this DRP is to provide a tool that can scaffold CT, vocabulary and conceptual development. The new vocabulary that is included in the text are words like data, input, plan, recalibrate, adjust, modify, customise, reset, programme, coordinates, copy, expand, and so forth.

\section{Language as a toolkit, lens and input}

The three characters (see Figure 1) in the story books each have characteristics that showcase a toolkit, a lens (screen) or 'input'. The storylines also allow two of the characters (Kate and Ben, the humans in the stories) to use input, to showcase their ideas on a screen or to use a little 'toolkit' to solve problems or to programme their little robot friend (Alex). By including these characteristics, I refer to the work of Gentner and Goldin-Meadow (eds. 2003) who propose that language serves as a 'toolkit', as a 'lens', and as 'input' during cognitive development.

Gentner and Goldin-Meadow (eds. 2003) proposes that language can serve as a 'toolkit' or 'aid' to develop conceptual knowledge by 'learning to direct one's own mental processes with the aid of words or signs [which] is an integral part of the process of concept formation' (Vygotsky 1962:59). Accordingly, a language 'toolkit' enables a child to make sense of, and to represent their unfolding concepts in a language system of codes. Prior to knowing the meaning of a word, they could not perform a certain action, or they would mimic understanding and use words without semantic backup. The notion of a linguistic 'toolkit' expands a child's existing representation of the world (Levine \& Baillargeon 2016). In the stories, Ben uses such a 'toolkit' to give instructions (through coding) to Alex, the robot - the toolkit enables the expansion of both Alex's and Ben's representations of reality.

Language is also a 'lens'. It 'shapes its speakers' perception of the world' (eds. Gentner \& Goldin-Meadow 2003:9) and allows one to look at concepts in different ways - depending on the linguistic lens you use (Levine \& Baillargeon 2016). In the stories, Kate has a lens - a screen - that represents her thoughts and ideas. The screen is indeed a lens or a visual representation of her knowledge. She gives the instructions to Ben, who uses the toolkit to create reality - thus to code or programme Alex, the robot friend. Language is also 'input' for conceptual development (Carey 2009):

$[L]$ inguistic input can have quite striking effects on conceptual development. Children who hear language relevant to a particular conceptual problem are more likely to solve that problem than children who do not. (Gopnik \& Meltzoff 1997:208-209)

In the story, Alex has a little 'input-screen' which Ben uses to programme the robot. Figure 4 showcases Kate's screen/ lens, Ben's toolkit and Alex's input screen.

The quality and the quantity of linguistic input influence children's development of the concepts represented by the words or language (Levine \& Baillargeon 2016). Linguistic input in school (Klibanoff et al. 2006) and in the home 


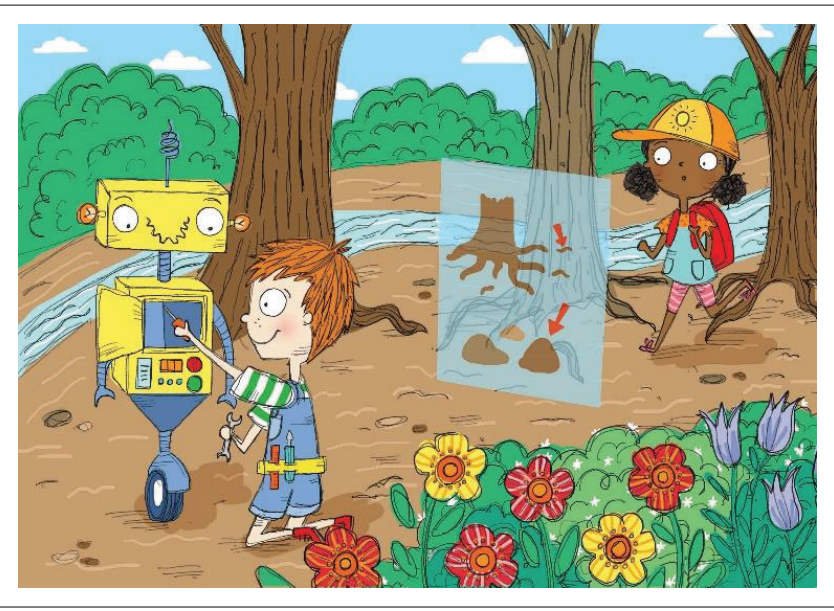

FIGURE 4: Kate's screen/lens, Ben's toolkit and Alex's input screen.

BOX 1: Alex the robot reacts on input.

In the stories, Alex the robot has a programming screen on its 'chest', which allows for linguistic input. The little robot reacts to input and follows the instructions given by Ben (with his toolkit), which was designed by Kate (visible on her screen/ lens). When Ben does not provide the correct input, the output (which in a sense ens). When Ben does not provide the correct input, the output (which in a sense represents conceptual understanding) malfunctions - the robot reacts incorrectly. 作 or know the vocabulary. Children often don't understand the 'input' or have limited exposure to 'input'. The result is also a 'malfunction' - poor results on assessments, indicating limited conceptual understanding.

environment (Gunderson \& Levine 2011; Levine et al. 2010) influence children's conceptual development.

The reading of these books is meant to provide children with a lens or a view on real situations that require $\mathrm{CT}$ in life. The storylines contain ample opportunities for children to see how they can implement the engineering design process of planning, implementing, improving and revising ideas. Oral interaction (and written interaction) on the screens of the characters in the books, through dialogic reading, is meant to help children expand their linguistic toolkits, which is, ultimately, aimed at also expanding their conceptual development. The content of the books is also designed in such a way that it provides quality and quantity linguistic input which is aimed at expanding children's digital skills and vocabulary.

\section{The principles of computational thinking, coding and other digital skills}

When developing educational material, such as a DRP, each component should model suitable content of the field, which is, in this instance, an integration of STEM learning with a central focus on those digital skills that have been defined by the DSfAC, namely CT, coding and programming. The storylines, character development, vocabulary and the illustrations of the DRP were designed to reflect the 'everyday' scenarios and principles of these fields so that children can relate to real life situations. Although many existing stories use artificial general intelligent (AGI) robots that can act like humans, and that are responsible for their own actions and do not need supervision or human input, the aim of this reading series is to provide children with ordinary, everyday situations which are already being used in society and where
$\mathrm{CT}$ and coding can be applied to programme robots. Artificial general intelligent robots are not yet part of the broader society. Artificial narrow intelligent (ANI) robots, on the other hand, are increasingly being introduced; for instance, self-driving aspects in cars such as navigation systems and speed control; and sorting machinery. To understand the principles of current applications of coding, I include a discussion of the principles of artificial intelligence (AI) in the theoretical component of this conceptual framework. These constructs are all included in the three story lines of the DRP.

Marwala and Hurwitz (2017) makes a case that users of AI technology should be informed about everyday use of AI technology, be knowledgeable about the data and algorithms used as input, and know how to use AI technology in an unbiased, responsible way. The three books in the series are written in such a way that children learn that both the creator and the user of an AI tool (such as a robot), should be informed and responsible for the output.

Artificial intelligence is increasingly being used for voiced controlled assistants such as navigation instruments, selfdriving cars and for conducting human tasks, such as sorting or categorising (Negishi 2018). Machines receive input from humans and the environment. They 'learn' through supervised learning (supervisors teach machines through input) and reinforcement learning (using input for trial and error and selfevaluation, while receiving rewards for accomplishments even though the reward is often delayed) (Dehaene 2020). Unsupervised learning (when a machine learns without supervision or reinforcement) is not yet a part of AI learning in general, although humans learn through unsupervised learning as well and have developed this ability though evolution of Homo sapiens (Dehaene 2020). Dehaene (2020) makes a case that machine learning can be compared to the way in which humans learn.

Often machines make mistakes, partly because of incorrect input. They then recalibrate or adjust by using error backpropagation to identify errors and to adjust parameters (Dehaene 2020). Both human minds and machines readjust or recalibrate by relying on the strength or weight of connections between neurons - biological and artificial, which receive input, weigh the importance of the input and determine whether or not to produce output and how to adapt current connections between neurons (Negishi 2018:4). Regular use of that particular connection between two neurons strengthens the connection, whereas irregular use results in pruning of the neurons or decreased connection strength.

During supervised learning, machines and humans either adjust existing connection weights between 'neurons' or form new connections, based on the input from others (Negeshi 2018:25). During unsupervised learning, machines (not yet often used) and humans rely on examples and previous experiences, with machines requiring numerous examples, while humans need far fewer (Dehaene 2020; https://dataia.eu/en/events/dataia-seminars-stanislas-dehaene). 
Connection strengths are adapted without being instructed about what the correct response is, mostly through trial and error which happens during reinforcement learning. With each positive outcome (often in the form of reward), the connection weight between neurons increases and each negative outcome requires recalibration or pruning.

The idea of a human making a plan to solve a problem by imagining various scenarios, creating a solution, implementing the solution, testing and improving the plan through adjustments, is the same process required to programme artificially intelligent machines - the engineering design process. Humans have problems, they devise a plan, code a robot through input and adjust the code when improvements are necessary.

The story lines in the books follow the same logic as the engineering design process. The logic of these designs is included in the discussions and example questions in the books. These discussions scaffold children's vocabulary development, and also their understanding of the design process itself, which they will use when they code, by using a simple programme such as Scratch Junior (Bers 2018; https:// www.scratchjr.org/) or more advanced programmes as they learn to programme machines.

\section{Core component 2: Iterative participatory approach with various role players}

Over the last few decades, a shift has taken place in how educational research is related to practice. Previously, it was thought that research yielded insights into educational practice and that findings could be applied in practice through a process of translation from research results and daily practice (Snow 2015). The assumption was that if the research process and methods were sound, applying the findings simply required interpretation and translation for application. Recently, though:

$[T]$ he traditional relationship between researcher, the producer of knowledge, and practitioner, the user of knowledge, was replaced by a commitment of the notion of two sources of knowledge (research and practice). (Snow 2015:461)

Both the researcher and practitioner's knowledge is now judged to be of equal importance to improve educational outcomes. In the instance of this project, practitioners include a variety of role players, such as teachers, parents, illustrators and linguists.

The second core component of the conceptual model is the utilisation of an iterative participatory approach (Holt \& Asagbra 2021; John et al. 2018; Purpura et al. 2021, in press) to involve various practicing role players in the development of the DRP. The goal of the participatory approach is to capitalise on the experience and expertise of each participant, both in the field of research and practice. By including the various contributors of the interdisciplinary team, consisting of education and developmental psychologists, teachers, children, parents and specialists in the fields of engineering, coding and programming, I designed the three dialogic reading books for young children.

Parent pairs who have children in preschool and of which at least one parent is a specialist in programming and engineering, were consulted on the story lines, characteristics of Ben, Kate and Alex, vocabulary use and how constructs are portrayed in the stories. Parents and teachers provided names of example stories (either on television or reading books) which were used to choose the story topics, design the characters and to inform the illustrators. Several conversations with linguists, researchers, teachers and parents took place in the preparation of the work, to ensure a discourse that is linguistically correct, yet appropriate for young children. For the illustrations, a local illustrator for children's books was identified to contribute to the design of the characters and the development of the illustrations to support the texts.

\section{Core component 3: Existing story examples}

The third core component of the conceptual model is the systemic utilisation of existing examples of teaching materials. Through the iterative participatory approach, parents and teachers indicated that Rusty Rivets, Puppy Dogs, Paw Patrol, Cars2 and Blaze are stories on television where little robots are presented with problems. Some of these stories contain a sayalong-phrase to teach basic vocabulary and ideas, which was a concept that I incorporated in the DRP. Other stories have characters with distinct features that contribute to children's understanding of required concepts. I used this notion by incorporating the already mentioned ideas of 'input', a 'toolkit' and a 'lens'. The story lines are also age-appropriate and clearly portray the design process, similar to what happens in existing stories. Recent children's books in this field of education (Buarque, Roberts \& Marwala 2019; Giridhar 2019; Negishi 2018; Smibert 2018) were also used as examples.

Lastly, an existing DRP for early numeracy, The Little Elephant's Big Adventures (https://earlymath.ericson.edu/familiesare-pivotal-in-designing-math-picture-books-for-children/), designed by Purpura and his team at the Purdue University (Purpura et al. in press), also contributed significantly to the structure and layout. These are dialogic reading books to develop mathematics-specific language and they consist of text and three example questions on each page which the reader can use to ask questions and prompt responses. The same structure was used in the design of Robot Dilemmas.

\section{Dialogue reading programme and the core components of the conceptual model}

The combination of the three intersecting core components jointly contributed to the development of five key features of the DRP: (1) story topics; (2) characters; (3) vocabulary; (4) constructs; and (5) illustrations. 


\section{Story topics}

Theoretical principles of $\mathrm{CT}$, coding and $\mathrm{AI}$, and current application of these technologies in society guided the identification of three story topics. Examples of existing stories were also used as a guideline to identify topics that provide ample opportunities to discuss the concepts that I had identified as a feasible target for learning. Lastly, parents, teachers and specialists were consulted to finalise three titles for the stories:

Alex Gets Stuck is about Kate, Ben and Alex who go on a hike. The storyline allows for an introduction to and discussions about: (1) the characters with their key features and specific characteristics (e.g. the ideas of input, a screen/lens and a toolkit; gender free robots, robots cannot think for themselves); (2) vocabulary (e.g. input, programme, customise, modify, deploy, script and syntax error); (3) main principles of CT, coding and programming robots (e.g. the difference between AGI and ANI robots); and (4) exhibitions of skills required during coding and programming tasks (e.g. being able to modify/adjust plans).

In the second book, Road Trip with Alex, the little robot becomes a self-driving car. Self-driving cars are one of the most promising fields of AI and a good example of how STEM disciplines are integrated. This storyline allows for discussions about: (1) the characteristics of robots (e.g. no gender, water may damage some robots), (2) principles of self-driving cars (e.g. input for a GPS system, speed control, self-park features); (3) principles of $\mathrm{CT}$, coding, AI and algorithm application (e.g. cameras/sensors help robots 'see' like humans see with our eyes, sensors can also help with adjustments such as speed); (4) how detailed code should be used as input; (5) what type of instructions can be given to a robot; and (6) the idea that the programming process usually includes adjustments, changes or modifications. The discussions introduce vocabulary such as 'coordinates', 'code', 'input', 'self-driving car', 'camera sensors', 'customise', 'modify' and 'deploy'.

The third book, Alex's Recycling Challenge, incorporates one of the most promising fields of coding and AI - sorting/ categorising based on key features - with an environmental issue, namely recycling. The book allows for discussions about: (1) which items can be recycled; (2) the idea that robots cannot think for itself although it can be trained by humans through coding; (3) why robots are being developed and how it can help humans; (4) the idea that robots don't have senses like humans, but use sensors, speakers and radar to receive input; (5) magnetic properties of metals; and (6) how to update or adjust a code when sufficient detail is not given in a code which results in malfunctions or mistakes of a robot. The discussions allow for opportunities to develop vocabulary such as customise, modify, deploy, robot, input, code, metal detector and adjust.

\section{Character development}

The development of the three characters followed theoretical guidelines (eds. Gentner \& Goldin-Meadow 2003) (especially related to theory about language as a lens, toolkit or input); discussions with parents, teachers and the illustrator; and examples of characters in existing stories. In the example DRP series for early numeracy (Purpura et al. 2021, in press), one encounters a boy, a girl and unisex character. The idea of using a boy, a girl and a unisex character was replicated in this DRP. Animals were excluded as options because I wanted the children to relate to the idea that a human boy or girl can programme a little robot. The robot is unisex and therefore has a unisex name, Alex. The boy and girl's names, as well as the robot's, had to be names that could be used in various cultural contexts but also had to be short and easy to remember. The characters also had to represent at least two ethnic groups.

Kate is a girl between 6 and 8 years of age and her hair is black. When she puts on her thinking cap, a programming screen pops up where all her ideas are featured - based on the idea of a language as a lens (eds. Gentner \& GoldinMeadow 2003). Ben follows her instructions to programme Alex by using his toolkit, which represents a linguistic toolkit. The idea of Kate's thinking cap and thinking screen also resonates with Vygotsky's theory (Kozulin 1990) that language and ideas become one when language becomes a mental function on its own.

Ben, also aged between six and eight, is a boy with ginger hair, who always has a toolkit strapped around his waist and wears a workman's overall. He programmes Alex by using his toolkit. The idea of Ben's toolkit also originates in the work of Gentner and Goldin-Meadow (eds. 2003) and Levine and Baillargeon (2016) who proposed that language as a toolkit scaffolds children's conceptual development.

Alex is an ANI robot - a 'one trick pony' (although the trick may be different in each story), while the typical TV robots are AGI machinery system robots who can perform almost similar cognitive tasks as humans without any human input. Alex 'engages' in supervised learning (input output mappings) and reinforcement learning, while many other TV characters 'use' unsupervised learning (which in reality is not yet realistically part of machine learning). Alex is a chatbot who is just as tall as the children. It has a programme screen on its chest. The robot is able to show facial expressions but does not talk. It can make a few beep sounds to indicate that something might be wrong. The programming screen on Alex's chest is used when Ben programmes the robot. The programming screen models the idea of language as input (eds. Gentner \& Goldin-Meadow 2003).

\section{Vocabulary}

In the stories, children hear words like 'data', 'coordinates', 'code', 'input', 'robot', 'self-driving car', 'camera sensors', 'plan', 'customise', 'modify', 'adjust', 'deploy', 'recalibrate', 'reset', 'expand' and 'select'. These words were identified from the programming interface that young children can use, and which is suggested in the Digital Skills curriculum: Scratch junior (Bers 2018), television programmes, conversations with coding 
specialists and educational neuroscience literature (e.g. Bers 2018; Dehaene 2020; Negishi 2018). A say-along-phrase ('Time to Alexify: Customise, modify and deploy!') in each book allows interactive participation in the stories, but also provides the opportunity where children can practice some of the words.

\section{Constructs from real life}

The three books in the DRP model real life instances where robots are currently being used in various societies and also include multiple discussion opportunities to teach STEM vocabulary and concepts, specifically focusing on the constructs of CT, coding and robotics. Eguchi (2017) describes robotics as a transformational tool for teaching CT, coding and engineering, and argues that applications of robotics in STEM is an effective way to integrate CT, coding and engineering skills. Each of the three storylines in the DRP models these principles of robotics, in which Alex - a little robot - is coded by one of the characters to solve problems.

Coding is another key element that is included in the storylines. Coding is the action of putting together sequences of instructions and debugging, or problem solving, and is often described as the new language of the digital society, needed to be understood by everyone in order to be able to interact in a culture and society heavily influenced by computer systems. Coding with robots shows children what they can create with technology, engaging children as producers and not merely consumers of technology (Greca Dufranc et al. 2020:4).

Bers (2018) notes that mathematical algorithms also form part of CT. An algorithm is 'a series of ordered steps taken in a sequence to solve a problem' (Greca Dufranc et al. 2020:4). It requires an understanding of the steps in a sequence to solve a problem; each storyline was designed to reflect how children can apply algorithms in robotics, coding and other STEM disciplines.

Furthermore, the engineering design process is portrayed in all three stories. This process consists of asking questions about a problem, imagining possible solutions, planning to implement a solution, implementing the solution, testing and improving the plan (Bers 2018). This is not a linear model one can bounce back and forth between steps. The key constructs of the design process were also used to choose words to include in the say along phrase ('Time to Alexify: Customise, modify, deploy!') where children learn the principles of a scientific approach to solve a problem: first one must customise a plan, modify the plan and deploy the changes. These ideas are portrayed in each of the stories, but also in the questions on each page so that children are engaged in discussions about the engineering design process.

\section{Illustrations}

A local illustrator of children's books contributed significantly to the design of the characters and the visual representations of the text. Because children rely on the illustrations to construct ideas and understand the terms, detailed and precise illustrations are pivotal. The use of colours and facial expressions allow children to identify with the pictures. The illustrations also clearly show the thinking cap, the toolkit and robot features, which also represent the various parts of linguistic input.

\section{Conclusion}

This article has argued that dialogue reading is an effective way to develop vocabulary and concepts consecutively. The DRP which I have discussed was designed to teach the constructs outlined in the DSfAC. This curriculum will soon be implemented in the early grades of South Africa. Computational thinking, coding and programming robots are digital skills required in the 21st century, and are also skills that are interwoven in the disciplines of STEM. Although theoretical frameworks exist that describe how teachers can plan and teach STEM literacy in a connected fashion, conceptual frameworks for the development of teaching material to support their teaching, such as a DRP have not yet received attention. To this end, I have proposed the interdisciplinary conceptual framework which served as bedrock for the development of a DRP and which addresses the concepts introduced in the new South African digital skills curriculum. I argue that if one cannot define the concepts needed to teach CT, coding and other STEM constructs through reading, one cannot study how a DRP will influence children's understanding.

By developing a conceptual model that grounds the design of teaching and learning material, I also proposed that a theoretical perspective alone is not sufficient and that theory should be supplemented by the perspectives of other role players though an iterative participatory approach and also by existing examples of stories used in the early grades. In the next phases of the current ongoing research project, the validity of the DRP will be assessed in a pilot study before conducting an experimental study to assess the workability and implementation of the DRP.

\section{Acknowledgements}

Th author acknowledges Zinelda Meiring who created the illustrations for the reading books; and also the GES program from the University of Johannesburg that funded this project.

\section{Competing interests}

The author declares that she has no financial or personal relationship(s) which may have inappropriately influenced her in writing this article.

\section{Author's contributions}

H.S.B. is the sole author of this article.

\section{Ethical considerations}

The adults who suggested ideas did so with informed consent. 


\section{Funding information}

This project was funded by a Global Excellence Stature 4.0 (GES) Postdoctoral Fellowship from the University of Johannesburg.

\section{Data availability}

Data sharing is not applicable to this article as no new data were created or analysed in this study.

\section{Disclaimer}

The author declares that the work is her own and that it was written in her own words. All citations from literature are acknowledged in-text and referenced. I agree that subject to the ownership of all intellectual property rights in this work, the approved version of this work may be published by the South African Journal of Early Childhood Education under my authorship.

\section{References}

Ansari, D., 2017, 'Why should educators care about cognitive neuroscience?', Learning \& the brain Conference, San Francisco, February 2017, Numerical Cognition Laboratory at the Department of Psychology \& Brain and Mind Institute at the Western University, April 07-09, 2017, San Francisco, CA.

Bers, M.U., 2018, 'Coding and computational thinking in early childhood: The impact of ScratchJr in Europe', European Journal of STEM Education 3(3), 8. https://doi. org/10.20897/ejsteme/3868

Bezuidenhout, H.S., 2018, 'Input for young children's number concept development', Doctoral dissertation, University of Johannesburg.

Buarque, F., Roberts N. \& Marwala, T., 2019, My first A.l. book: Artificial intelligence and learning, ISBNAgency.com, Amazon direct Kindle publishing, Johannesburg.

Bybee, R.W., 2010, What is STEM education? Science 329(5995), 996. https://doi. org/10.1126/science.1194998

Carey, S., 2009, The origin of concepts, Oxford University Press, Oxford.

Carey, S., Zaitchik, D. \& Bascandziev, I., 2015, 'Theories of development: In dialog with Jean Piaget', Developmental Review 38, 36-54. https://doi.org/10.1016/j. dr.2015.07.003

Chomsky, N., 2014, Aspects of the theory of syntax, Vol. 11, MIT Press, Cambridge, MA.

Chu, H.E., Martin, S.N. \& Park, J., 2019, 'A theoretical framework for developing an intercultural STEAM program for Australian and Korean students to enhance science teaching and learning' International Journal of Science and Mathematics Education 17(7), 1251-1266. https://doi.org/10.1007/s10763-018-9922-y

Clements, D. \& Sarama, J., 2015, 'Discussion from a mathematics education perspective', Mathematical Thinking and Learning 17(2-3), 244-252. https://doi. org/10.1080/10986065.2015.1016826

Clements, D.H. \& Sarama, J., 2016, 'Math, science, and technology in the early grades', The Future of Children 26(2), 75-94. https://doi.org/10.1353/foc.2016.0013

Dehaene, S., 2009, Reading in the brain. The new science of how we read, Penguin, London.

Dehaene, S., 2011, The number sense: How the mind creates mathematics, Oxford University Press, Oxford.

Dehaene, S., 2013, 'Inside the letterbox: how literacy transforms the human brain', Cerebrum: The Dana Forum on Brain Science 2013, 7.

Dehaene, S., 2020, How we learn: Why brains learn better than any machine... for now, Penguin, New York.

Department of Basic Education, in press, Introducing digital skills for all into GET: Curriculum framework grades R-9, Department of Basic Education, Pretoria.

De Villiers, H.S., 2015, Die werkbaarheid van die Afrikaanse vertaling van ' Wiskunde diagnostiese toets vir die Grondslagfase, University Press, Johannesburg.

Dowker, A. \& Nuerk, H.C., 2016, 'Linguistic influences on mathematics', Frontiers in Psychology 7, 1035. https://doi.org/10.3389/fpsyg.2016.01035

Eguchi, A., 2017, 'Bringing Robotics in Classrooms', in M. Khine (eds), Robotics in STEM Education, Springer, Cham. https://doi.org/10.1007/978-3-319-57786-9_1

Gallistel, C.R. \& King, A.P., 2011, Memory and the computational brain: Why cognitive science will transform neuroscience, Vol. 6, Blackwell Publishing, Singapore.

Gentner, D. \& Goldin-Meadow, S. (eds.), 2003, Language in mind: Advances in the study of language and thought, MIT Press, Cambridge.
Giridhar, H., 2019, Al for Kids: A first look into the fascinating concept of Artificial Intelligence that is disrupting the world, Independently published.

Gopnik, A. \& Meltzoff, A.N., 1997, Words, thoughts, and theories, MIT Press, Cambridge, MA

Greca Dufranc, I.M., García Terceño, E., Fridberg, M., Cronquist, B. \& Redfors, A., 2020, 'Robotics and early-years STEM education: The botSTEM framework and activities', European Journal of STEM Education 1, 1-13.

Gunderson, E.A. \& Levine, S.C., 2011, 'Some types of parent number talk count more than others: Relations between parents' input and children's cardinal-number knowledge', Developmental Science 14(5), 1021-1032. https://doi.org/10.1111/ j.1467-7687.2011.01050.x

Holt, Y. \& Asagbra, E., 2021, 'Implementing dialogic reading intervention through community-based participatory research: A tutorial', Language, Speech, and community-based participatory research: A tutorial', Language, Speech, and
Hearing Services in Schools 52(1), 4-15. https://doi.org/10.1044/2020 Hearing Services
LSHSS-19-00100

John, M.S., Sibuma, B., Wunnava, S., Anggoro, F. \& Dubosarsky, M., 2018, 'An iterative participatory approach to developing an early childhood problembased STEM curriculum', Grantee Submission 3(3), 7. https://doi.org/10.20897/ ejsteme/3867

Kelley, T.R. \& Knowles, J.G., 2016, 'A conceptual framework for integrated STEM education', International Journal of STEM Education 3(1), 1-11. https://doi. org/10.1186/s40594-016-0046-z

Klibanoff, R.S., Levine, S.C., Huttenlocher, J., Vasilyeva, M. \& Hedges, L.V., 2006 'Preschool children's mathematical knowledge: The effect of teacher "math talk"' Developmental Psychology 42(1), 59. https://doi.org/10.1037/0012-1649.42.1.59

Kozulin, A., 1990, 'The concept of regression and Vygotskian developmental theory', Developmental Review 10(2), 218-238. https://doi.org/10.1016/02732297(90)90011-R

Levine, S.C. \& Baillargeon, R., 2016, 'Different faces of language in numerical development', Core Knowledge and Conceptual Change, 127-150. https://doi. org/10.1093/acprof:0so/9780190467630.003.0008

Levine, S.C., Suriyakham, L.W., Rowe, M.L., Huttenlocher, J. \& Gunderson, E.A., 2010, 'What counts in the development of young children's number knowledge?', Developmental Psychology 46(5), 1309. https://doi.org/10.1037/a0019671

Lu, J.J. \& Fletcher, G.H., 2009, 'Thinking about computational thinking', in Proceedings of the 40th ACM technical symposium on Computer science education, pp. 260-264.

Marwala, T. \& Hurwitz, E., 2017, Artificial intelligence and economic theory: Skynet in the market, Vol. 1, Springer International Publishing, Cham.

Mol, S.E., Bus, A.G., De Jong, M.T. \& Smeets, D.J., 2008, 'Added value of dialogic parent-child book readings: A meta-analysis', Early Education and Development parent-child book readings: A meta-analysis', Early Education
19(1), 7-26. https://doi.org/10.1080/10409280701838603

Negishi, M., 2018, A textbook on Artificial Intelligence: My cell phone can think, Neuroverb, Milford, CT.

Purpura, D.J., Napoli, A.R. \& King, Y., 2019, 'Development of mathematical language in preschool and its role in learning numeracy skills', in Cognitive foundations for improving mathematical learning, pp. 175-193, Academic Press, Cambridge, MA

Purpura, D.J., Napoli, A.R., Wehrspann, E.A. \& Gold, Z.S., 2017, 'Causal connections between mathematical language and mathematical knowledge: A dialogic reading intervention', Journal of Research on Educational Effectiveness 10(1), 116-137. https://doi.org/10.1080/19345747.2016.1204639

Purpura, D.J., Schmitt, S.A., Napoli, A.R., Dobbs-Oates, J., King, Y.A., Hornburg C.B. et al., 2021, 'Engaging caregivers and children in picture books: A family-
implemented mathematical language intervention', Journal of Educational implemented mathematical language intervention', Journal of Educationa
Psychology, Advance online publication. https://doi.org/10.1037/edu0000662

Sarnecka, B.W., 2014, 'On the relation between grammatical number and cardinal numbers in development', Frontiers in Psychology 5, 1132. https://doi. numbers in development', Fron
org/10.3389/fpsyg.2014.01132

Smibert, A., 2018, Artificial intelligence: Thinking machines and smart robots with science activities for kids (Build it yourself), Nomad Press, Norwich.

Snow, C.E., 2015, '2014 Wallace Foundation distinguished lecture: Rigor and realism Doing educational science in the real world', Educational Researcher 44(9), 460-466. https://doi.org/10.3102/0013189X15619166

Spelke, E.S., 2017, 'Core knowledge, language, and number', Language Learning and Development 13(2), 147-170. https://doi.org/10.1080/15475441.2016.1263572

Sulzby, E., 1985, 'Children's emergent reading of favorite storybooks: A developmental study', Reading Research Quarterly 20(4), 458-481. https://doi.org/10.1598/ Study', Readin

Tunmer, W.E. \& Hoover, W.A., 2019, 'The cognitive foundations of learning to read: A framework for preventing and remediating reading difficulties', Australian Journal of Learning Difficulties 24(1), 75-93. https://doi.org/10.1080/1940415 8.2019.1614081

Vygotsky, L.S., 1962, Thought and word, MIT Press, Cambridge, MA.

Vygotsky, L., 1978, 'Interaction between learning and development', Readings on the Development of Children 23(3), 34-41.

Vygotsky, L.S., 1986, Thought and language, rev. edn. MIT Press, Cambridge, MA.

Whitehurst, G.J., Falco, F.L., Lonigan, C.J., Fischel, J.E., DeBaryshe, B.D., ValdezMenchaca, M.C. et al., 1988, 'Accelerating language development through picture book reading', Developmental Psychology 24(4), 552. https://doi.org/10.1037/ 0012-1649.24.4.552

Wing, J.M., 2008, 'Computational thinking and thinking about computing', Philosophical Transactions of the Royal Society A: Mathematical, Physical and Engineering Sciences 366(1881), 3717-3725. 